\title{
Fuzzy C-Means Partition Cluster Analysis and Validation Studies on a Subset of CiteScore Dataset
}

\author{
T.N. Borovik, V.V. Zuev, E.V. Preobrazhenskaya, I.V. Belousov, N.S. Baranova, A.V. Minin
}

\begin{abstract}
The article deals with promising areas of application of pulsed laser welding for products made of silver-based alloys. The results of experimental studies to improve the quality of the welded joint and the efficiency of the welding process with the use of activated absorption additives are presented.
\end{abstract}

Index Terms: weld quality, pulsed laser welding, absorption, reflection

\section{INTRODUCTION}

The choice of laser welding technology should be preceded by a sufficiently deep technical and economic analysis of the proposed technological problem, based on the fact that laser processing should be used in case of impossibility or difficulty of using traditional inexpensive methods of processing materials, including welding.

The choice of the laser type should take into account the total power of the laser radiation, its loss due to reflection from the welded surfaces, the efficiency.

According to the method of laser welding can be divided into pulsed and continuous. The pulse method can be used for spot welding of joints of various configurations, as well as seam welding of butt joints, obtained as a result of successive overlay of welded points with overlapping irradiation zones.

Initially, pulsed laser welding began to develop and found application for point connections.

The following main rational applications of pulsed laser welding are noted:

- spot and seam welding of parts of electrovacuum devices made of refractory metals and alloys;

- seam welding of butt joints of thin-walled elements, which have high requirements for residual stresses and the quality of the seam surface;

- welding of dissimilar metals and alloys;

- spot welding in microelectronics and precision instrumentation;

- welding in hard-to-reach places, easily deformable parts in conditions of intensive heat removal, parts requiring a minimum zone of thermal influence and maximum technological purity, etc.

Revised Manuscript Received on July 09, 2019.

T.N. Borovik, V.V. Zuev, E.V. Preobrazhenskaya, I.V. Belousov, N.S. Baranova, A.V. Minin, Assistant Professor, MIREA - Russian Technological University, 119454, Russia

borovik@mirea.ru
When using a laser for spot welding of parts, it is necessary to choose the type of laser, pulse parameters (energy, pulse duration, position of the welded point relative to the welded surface) and to prepare the welded surfaces in a certain way. In addition, depending on the technological problem to be solved, one of the following main restrictions on the parameters of the impact zone is possible:

- limited size of the heat-affected zone (welding of metal foil with semiconductor, welding near the thermally sensitive element);

- limited release of the material from the radiation exposure area (the condition is related to the requirement of high strength of the welded joint);

- temperature gradient is limited;

- minimum contact time of solid and liquid phases, to avoid the formation of intermetallic layers and the appearance of the embrittlement of HAZ of the weld;

- maximum depth of penetration without release of supply so as not to reduce strength of a welded joint;

- necessary protective atmosphere or space parts to be joined in a vacuum to avoid oxidation of the surface of the materials.

Simultaneous fulfillment of all technological requirements is quite difficult. If the material is considered to be a solid body with some thermophysical characteristics, the problem is reduced to finding the optimal pulse duration, the required specific radiation power and the spatial distribution of specific power [1-10].

\section{MATERIALS AND METHODS}

The use of metal materials with a low reflectance as an activated melting additive reduces the heating time of the surface of the welded product to a temperature at which the reflection is reduced. Activating the penetration additives can also act as an" additional" source of heating. However, the choice of the additive material seems to be a difficult task due to the lack of both theoretical ideas about the melting mechanism and experimental studies of the radiation absorption by a surface that is inhomogeneous in chemical composition and thermophysical properties.

To determine the method of alloying, welding of silver samples with a cross section of $5 \times 0.5 \mathrm{~mm}$ was performed. as an alloying element, we use Nickel in the form of a gasket with a thickness of $0.1 \mathrm{~mm}$, wire $\mathrm{d}=0.2 \mathrm{~mm}$ on

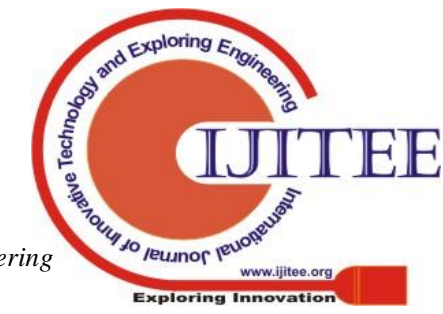


the surface in the direction of the joint, powder material with a granulation of $0.01 \div 0.005 \mathrm{~mm}$.

The Assembly of the samples was carried out under the microscope, back to back, without a gap, and then injected alloying element. When assembling the sample, the Nickel gasket was placed in the butt joint between the silver plates. Nickel wire and powder were placed over the butt joint.

Welding of samples was performed at a pumping voltage of $750 \mathrm{~V}$ and defocusing 0 along the joint.

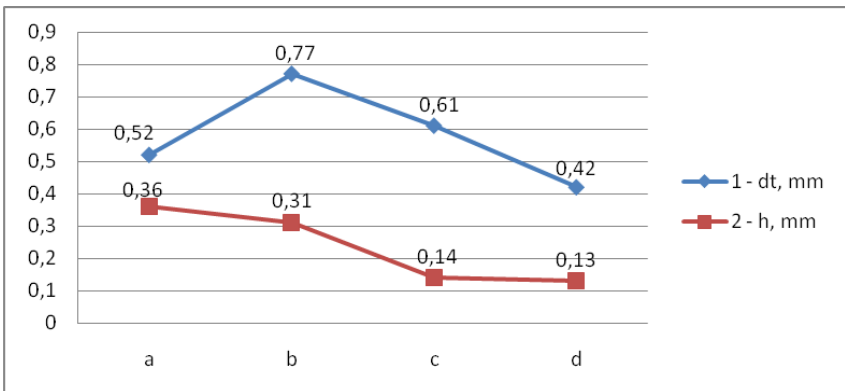

a) Nickel strip; b) Nickel wire;

c) Nickel powder; d) silver sample.

Figure 1 - effect of the doping method $(\mathrm{UN}=750 \mathrm{~V}, \Delta \mathrm{f}=0)$ on: 1 - diameter of the welded point, 2 - depth of penetration of the welded point

Then, the diameter of the welded point and the penetration depth were measured on the fracture of the samples using a microscope:

- sample, doped Nickel strip form the surface of the bath was afloat with typical signs of crystallization and splashes;

- on the sample doped with Nickel wire, the shape of the bath surface after crystallization is asymmetrically elongated in the direction of the joint, in the center of the seam near the axis there were surfacings with traces of crystallization, the crystallite axes are parallel to the seam axis, splashes were observed along the seam periphery;

- sample, doped Nickel powder, after crystallization observed burn-through, craters, has a through penetration, and cracks.

The results of measuring the diameter and depth of penetration of a single welded point presented on the graph showed that the efficiency of penetration in all cases increases.

A slight increase in the penetration depth when using the powder additive as an activating melting is probably due to the lack of contact between the welded surface and the powder surface, as well as the heat sink along the periphery of the radiation exposure zone. The introduction of an additive through the interlayer and wire from a technological point of view the most simple and allows you to change in a wide range of the number to activate the penetration of the additive on the surface of the irradiation.

As a result of the study of methods of doping, it was determined that:

- the diameter of the welded point varies from 0.52 to 0.77 $\mathrm{mm}$;

- the penetration depth varies from 0.14 to $0.36 \mathrm{~mm}$.

On the basis of the above, it should be concluded - doping with wire is the most optimal way of doping.

To conduct a study that determines the effect of the alloying material on the dimensions of the weld pool, collect several samples and weld them each time changing the filler material.

Table 1 - results of the study

\begin{tabular}{|c|c|c|}
\hline & $\mathrm{d}, \mathrm{mm}$ & $\mathrm{h}, \mathrm{mm}$ \\
\hline $\mathrm{Ag}$ & 0,42 & 0,14 \\
\hline $\mathrm{Ag}+\mathrm{Cu}$ & 0,33 & 0,07 \\
\hline $\mathrm{Ag}+\mathrm{Ni}$ & 0,58 & 0,33 \\
\hline $\mathrm{Ag}+\mathrm{Ti}$ & 0,60 & 0,50 \\
\hline
\end{tabular}

\section{RESULTS AND DISCUSSION}

Using the rule of additivity, we estimate the increase in the absorption coefficient $A_{c m}$ for the irradiation surface, part of which is occupied by the activated absorption additives according to the ratio:

$$
A_{c m}=\frac{F_{a n n}}{F_{c m}} \cdot\left(1-R_{a n n}\right)+\frac{F_{c m}-F_{a n n}}{F_{c m}} \cdot\left(1-R_{c m}\right)
$$

$R_{\text {ann }}, R_{c m}$ - reflection coefficient of the additive and the welded metal, respectively.

$F_{a n n}, F_{c m}$-the surface area of the irradiation of the additive (in the case of wire - projection) and the welded point, respectively.

Application of the additivity rule by the absorption coefficient can be considered as the first approximation to the model of laser radiation penetration by inhomogeneous chemical composition and thermophysical properties of the surface. The energy absorbed by the additive is transferred to the weld metal by heat transfer in contact during the joint movement of the liquid phases and their mixing. The difference in viscosity, density and temperature of contacting liquids, as well as the uneven force field acting on the surface, makes it difficult to conduct theoretical analysis. Evaluation of the effectiveness of the activated absorption additive titanium welding silver shows the feasibility of such a process.

Calculating the formula (1), write in the table the data:

Table 2 - absorption coefficients of samples with wire additive

\begin{tabular}{|c|c|}
\hline & Energy absorption coefficient, $\%$ \\
\hline $\mathrm{Ag}$ & 0,1 \\
\hline $\mathrm{Ag}+\mathrm{Cu}$ & 0,9 \\
\hline $\mathrm{Ag}+\mathrm{Ni}$ & 2,7 \\
\hline $\mathrm{Ag}+\mathrm{Ti}$ & 5,8 \\
\hline
\end{tabular}

The average value of the absorption coefficient for the selected method of input of the activating absorption additive increases from $0.1 \%$ to $5.8 \%$, which leads to an increase in the volume of the single weld point and, consequently, the cross section of the seam.

It is known that the maximum energy loss is typical for the initial stage of 
the pulse action because the reflection coefficient from the cold solid surface has a maximum value.

Reduction of reflection at this stage can be achieved by various methods:

- coating with high absorption coefficient;

- creation of the surface relief increases the absorption;

- use of absorption-activating additives.

Evaluation of the efficiency of pulse energy for the formation of a compound using the energy utilization coefficient shows that this value is reduced when welding silver to $0.27 \%$.

The value of $K$ is defined as:

$$
K=\frac{W_{w p}}{W_{p e}}
$$

$W_{w p}$ - the amount of heat spent on melting the welded point, J;

$W_{p e}$ - pulse energy, $\mathrm{J}$.

Calculated by the formula (2), the coefficient of radiation energy use increases from $0.3 \%$ to $5.1 \%$. Silver samples doped with titanium wire showed the greatest result.

\section{CONCLUSION}

It is experimentally shown that the use of Nickel wire as an activating absorption additive in pulsed laser welding of silver is increased by $0.1 \%$ to $5.8 \%$, which leads to an increase in the volume of the single weld point and, consequently, the cross-section of the weld. Based on the assessment of the size of a single welded point, it is shown that the efficiency of radiation energy increases from $0.3 \%$ to $5.1 \%$.

The introduction of an additive in the form of wire from a technological point of view is the simplest and allows you to change in a wide range of the number of activating absorption additives on the irradiation surface.

\section{REFERENCES}

[1] Demenkova T.A., Tomashevskaya V.S., Shirinkin I.S. Mobile Applications For Tasks Of Distance Learning // Russian Technological Journal, 2018. Volume 6, Issue 1, P. 6-19. URL: https://rtj.mirea.ru/upload/medialibrary/210/RTZH_2018_1_5_19.pdf

[2] Borovik T.N., Yampolskii V.M., Krasheninnikov A.I. Design repaired products from alloys based on silver with the use of laser welding // Design. Theoryand Practice, 2012, 10, p. 32-44.

[3] Borovik T.N., Belousov I.V. Influence of technological factors on the quality of joints in pulsed laser welding // Research: theory, methods and practice: materials of the International scientific-practical conference», 2017. - p. 271-273. - ISBN 978-5-9500297-4-5

[4] Borovik T.N., Belousov I.V. The effect of defocusing on the occurrence of burns in pulsed laser welding of silver // Research: theory, methods and practice: materials of the International scientific-practical conference, 2017. - p. 220-221. - ISSN 2412-0537.

[5] Borovik T.N., Belousov I.V. Practical application in the educational environment of modern technologies in the field of materials // Educational environment today: theory and practice: materials of the International scientific-practical conference,2017. - C. 77-78. - ISBN 978-5-9500127-8-5.

[6] Katayama S. Handbook of laser welding, Technosphere, 2015.

[7] Djevello E.S., etc. Specifics of Management Quality Implementation to Information Systems and Products // Proceedings of the 2018 International Conference "Quality Management, Transport and Information Security, Information Technologies", IT and QM and IS, 2018, 8524995, p. 40-43.

[8] Nazarenko M.A., etc. Main directions of higher education regionalization process as an integral part of social partnership in society (The problems of inclusive education) // International Journal of Engineering and Technology(UAE). 2018. Volume 7, Issue 4.36. P. 1135-1138.
[9] Cheremukhina Y.Y., etc. The process of working with claims in the quality management system of an enterprise of the radio-electronic industry // International Journal of Engineering and Technology(UAE). 2018. Volume 7, Issue 4.36. P. 67-68.

Nazarenko M.A., etc. Model end-to-end integrated quality management // International Journal of Engineering and Technology(UAE). 2018. Volume 7, Issue 4.36. P. 60-63. 